\title{
Prospective Cross-Sectional Study of the Uses of Non-prescription Analgesics among Hail Residents
}

\author{
Hadeel M. Alluqmani ${ }^{1}$, Wafa O. Alharbi ${ }^{1}$, Sarah B. Al Marri ${ }^{1}$, Meead M. Alanzi ${ }^{1}$, Laila Y. Alanzi ${ }^{1}$, \\ Weiam A. Hussein ${ }^{2,3^{*}}$, Weam M. A. Khojali ${ }^{2,4}$ and Farhan A. Alshammari ${ }^{5}$ \\ ${ }^{1}$ Graduated Student, College of Pharmacy, University of Hail, 2240/Hail, KSA \\ ${ }^{2}$ Department of Pharmaceutical Chemistry, College of Pharmacy, University of Hail, \\ 2240/Hail, KSA; white.wf.rose@gmail.com,w.hussein@uoh.edu.sa. \\ 3Department of Pharmaceutical Chemistry, College of Pharmacy, Aden University, 6075/Aden, Yemen \\ ${ }^{4}$ Department of Pharmaceutical Chemistry, College of Pharmacy, Omdurman Islamic University, \\ 14415/ Al Khartoum, Sudan \\ ${ }^{5}$ Department of Pharmaceutics, College of Pharmacy, University of Hail, 2240/ Hail, KSA
}

\begin{abstract}
The aim of this paper was to describe the general status of the use of non-prescription analgesics (NPA) among the residents of Hail city to ensure the safe use of non-prescription analgesics. One hundred participants with different diseases were studied consecutively from January to March 2020. Data were collected with an online, semi-structured questionnaire; the obtained data were converted into statistical data using Microsoft Excel 2013. Most participants were taking a single, non-prescription analgesic (87.5\%), while combination analgesic products were used by only $12.5 \%$ of participants. Using over-the-counter analgesics is common among residents of Hail, and most of those studied use these products in moderation and do not exceed the recommended dose. Acetaminophen is the most widely used product, but people also use NSAIDs and amphetamine-like products. The use of over-the-counter analgesics is common among residents of Hail, and most of the participants in this study use these products in moderation and do not exceed the recommended dose; therefore, exposure of patients to an increased risk of adverse effects of these products is out of the question, and this indicates that a large group of people in this region knows the risk of analgesics overuse. New studies are needed to help improve the approaches to the use of NPA drugs.
\end{abstract}

Keywords: Analgesics, Hail City, Non-Prescription Analgesics, Semi-Structured Questionnaire

\section{Introduction}

Non-prescription analgesics (NPA) are generally bought in enormous amounts, with a wide accessibility of medications for easing different kinds of pain in distribution. The worldwide NPA analgesics market is projected to record a steady extension through 2022. The market is assessed to surpass incomes worth US\$ 20,000 before the finish of $2022^{1}$. Analgesics, also called painkillers, are drugs that assist relieve pain without influencing consciousness, modifying sensory perception, or inhibiting impulse conduction. These medications incorporate paracetamol, nonsteroidal anti-inflammatory drug drugs (NSAIDs), and narcotic medications like morphine. Analgesics are utilized for treating pain because of many reasons like for examples; physiological injuries, medical procedures, inflammation, neuropathic

${ }^{*}$ Author for correspondence 
conditions, and cancer therapies. Rising web use has empowered different online business stages to work together with drug producers to convey drugs like analgesics at the doorstep of buyers ${ }^{2}$. Up to $70 \%$ of the populace in Western nations utilizes analgesics reliably, for migraines, other particular pains, and febrile sickness. Over-the-counter medicine is also called OTC or nonprescription medicine. These terms refer to medicine you can purchase without a prescription. They are safe and effective, provided you follow the directions on the label and use only as directed by your healthcare professional. The most painful condition that may cause severe pain is kidney stones, which are formed due to excess of the components that form stones. Due to a decrease in urine volume, severe pain occurs in the back and side when stones move from the kidney to the ureter. The pain may also radiate to the groin area and the lower abdomen. There are other pain cases, such as trauma, cancer, labour, urinary tract infection, burns, fibromyalgia and dental work. Most of these cases require analgesic medication, such as after surgery, arthritis and cluster headache ${ }^{3}$. About 15,000 individuals lose their life each year in the United States due to complications from NSAID treatment. Given the seriousness of pain, we confirm that patients using NPA drugs may represent a distinct class at rise of coincidental overdose ${ }^{4}$. Based on the above discussions, this study identified the use of NPA by the population in Hail city to ensure the secure use of NPA.

\section{Materials and Methods}

One hundred patients of both sexes aged less than 20 to 40-50 years, with a history of taking NPA, were studied in a prospective style from January to March 2020. Data were collected via online responses to a semi-structured questionnaire designed for this study, including demographic details (such as age, sex, education level... etc.), and facts about the analgesics used (type, frequency, time of use, and quantity). The Research Ethics Committee of the University of Hail, (Application No. 139) approved the study. The obtained data were converted into statistical data using Microsoft Excel 2013. The sample size was calculated by utilizing the online appliance Raosoft ${ }^{\circ}$ sample size calculator using a 5\% margin of error, a confidence level of $95 \%$, population size of $407.000^{5}$ and response distribution of $50 \%$; the estimated sample size was 197 (Raosoft Sample Size Calculator) ${ }^{6}$. This is the sample size we were supposed to reach, according to the population of the city of Hail. However, we only reached 100.

\section{Results}

To identify the usage NPA by the population in Hail city, 100 participants with different diseases were studied in an organised manner from January to March 2020. The members involved in the study had a mean age of 25 years (range $<20$ to 50 years) and were predominantly female. Thus, $81 \%$ were females and $19 \%$ were males, proportional to about $(\sim 4: 1)$ female to male ratio. $80 \%$ were in the $20-30$ years age group, while $7 \%$ were in the age group of $30-40$ years and $11 \%<20$ years. Only $2 \%$ were $40-50$ (Table 1 ).

Table 1. Demographic characteristics of patients participated in the study

\begin{tabular}{|c|c|}
\hline & Frequency \% \\
\hline Total number of patients & 100 \\
\hline Gender & \\
\hline Male & $19 \%$ \\
\hline Female & $81 \%$ \\
\hline Age yrs. $($ mean $\pm S D)$ & $(25.44 \pm 4.35)$ \\
\hline$<20-40$ & $98(98 \%)$ \\
\hline $40-50$ & $2(2 \%)$ \\
\hline
\end{tabular}

Of the participants, $4 \%$ were uneducated, $5 \%$ were less than high school diploma-holders, $21 \%$ were high school diploma-holders, $57 \%$ were bachelor's-holders, and $13 \%$ were master or $\mathrm{PhD}$ holders (Figure 1).

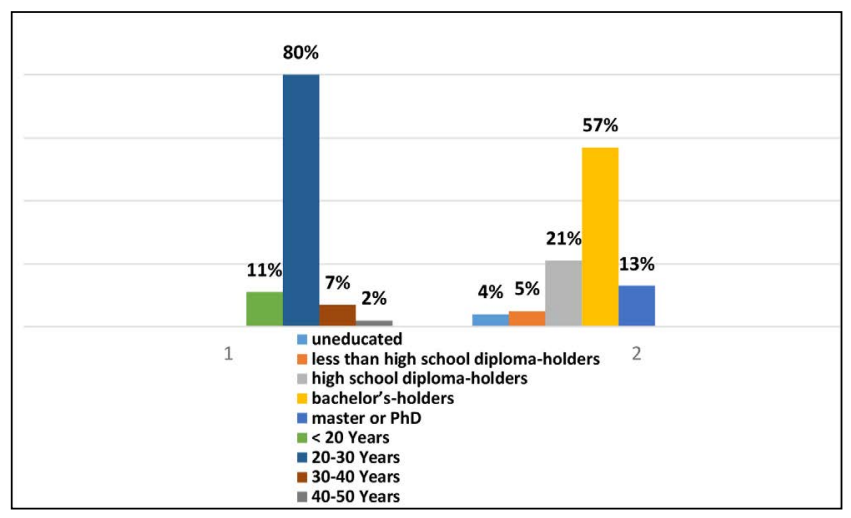

Figure 1. Distribution of participants according to education level in respect to age group. 
Most of those who participated in the study (32\%) were diagnosed with painful conditions (how long does pain last) less than a year, while about $21 \%$ seemed to start diagnosis from $1-5$ years, $17 \%$ from 5 to 10 years. About $30 \%$ of participants started the diagnosis over 15 years ago (Figure 2). All the participants are still suffering and taking the NPA until the time of writing this study.

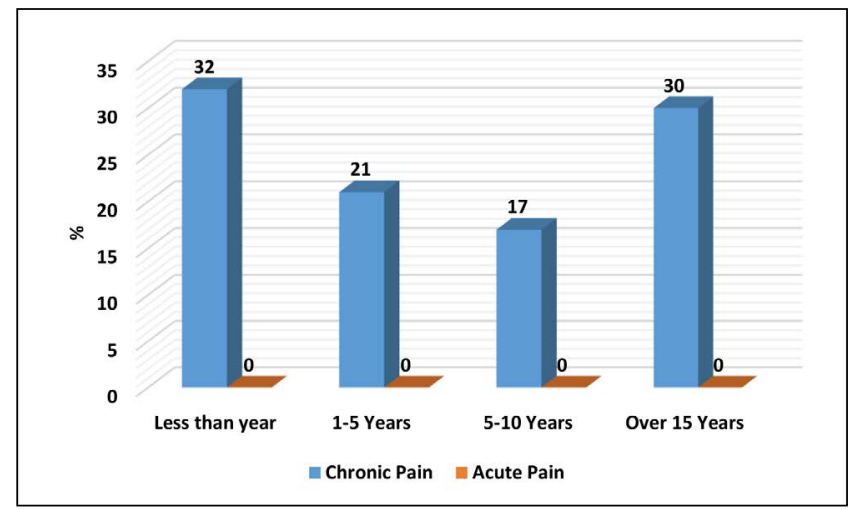

*Acute pain usually does not last longer than six months?.

Figure 2. The percentage of patients pain intensity in respect to years of the start of the diagnosis.

About $18 \%$ of participants take analgesics on a regular schedule, while $82 \%$ take them any time when they have a pain attack. Only $9 \%$ of participants took analgesics after talking with professional doctors, especially when they exceeded the recommended dose, while 91\% took it any time they had a pain attack without consulting their doctors first. Most participants took a single nonprescription analgesic (87.5\%), while combination analgesics (analgesic combination products either have acetaminophen, an NSAID such as ibuprofen or naproxen, codeine, or another opioid as one of their ingredients) products were used by only $12.5 \%$ (Table 2 ).

Table 2. Type and manner of taking analgesics

\begin{tabular}{|c|c|c|c|c|c|c|c|c|}
\hline $\begin{array}{l}\text { Number of } \\
\text { Participants }\end{array}$ & \multicolumn{2}{|c|}{ Analgesics Most Frequently Used } & \multicolumn{2}{|c|}{$\begin{array}{l}\text { Consulted } \\
\text { Doctor }\end{array}$} & \multicolumn{2}{|c|}{$\begin{array}{c}\text { Manner of Taking } \\
\text { Analgesics }\end{array}$} & \multicolumn{2}{|c|}{ Consulted Leaflet } \\
\hline \multirow{3}{*}{100} & ${ }^{\star}$ Mono- & ${ }^{* *}$ Combined & Yes & No & $\begin{array}{l}\text { On Regular } \\
\text { Schedule }\end{array}$ & Anytime & Yes & No \\
\hline & analgesics & analgesics & \multirow[t]{2}{*}{$9 \%$} & \multirow[t]{2}{*}{$91 \%$} & \multirow[t]{2}{*}{$18 \%$} & \multirow[t]{2}{*}{$82 \%$} & \multirow[t]{2}{*}{$55 \%$} & \multirow[t]{2}{*}{$45 \%$} \\
\hline & $87.5 \%$ & $12.5 \%$ & & & & & & \\
\hline
\end{tabular}

${ }^{\star}$ A single agent

${ }^{\star}$ Combined analgesic products either have acetaminophen, an NSAID such as ibuprofen or naproxen, codeine, or another opioid as one of their ingredients.
Among the analgesics most frequently reported, 53\% are used to treat headache and migraine, $34 \%$ menstrual cycle pain, 5\% osteoarthritis, $3 \%$ rheumatoid arthritis, and $1 \%$ for myocardial infarction (MI), neuropathy, and kidney disorders, respectively (Figure 3).

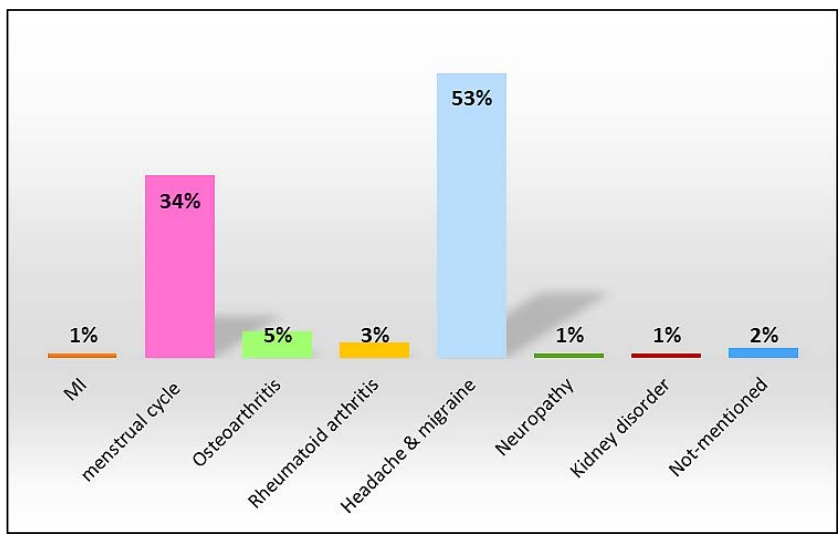

Figure 3. Causes of chronic pain among patients participated in the study.

Acetaminophen was used by $61 \%$ of participants, followed by NSAIDs (about 35\%) and amphetaminelike products stimulants which are usually found in nasal decongestants, bronchodilators, hunger suppressants, and energy tablets; the ingredients of concern are like ephedrine and pseudoephedrine ${ }^{8}$ at about $4 \%$. About $66 \%$ used the specified analgesic $\leq$ - twice a week, while $34 \%$ used it over three times a week. Concerning dosing intervals, about $58 \%$ used the specified analgesic $\leq$ - twice a week, while $34 \%$ used it over three times a week (Table 3).

None of the participants surpassed the suggested dose of acetaminophen or ibuprofen and naproxen (Table 4). Some participants were taking acetaminophen plus a combined analgesic medication containing acetaminophen; hence, we were unable to decide whether 
Table 3. Type of analgesics used with their usage frequency per week

\begin{tabular}{|c|c|c|c|c|c|}
\hline $\begin{array}{l}\text { Number of } \\
\text { Participants }\end{array}$ & \multicolumn{3}{|c|}{ Analgesics Most Frequently Used, As Percentage } & \multicolumn{2}{|c|}{ Frequency of Analgesic Use a Week } \\
\hline \multirow{3}{*}{100} & & & Amphetamine-Like & $\begin{array}{c}\leq- \text { Twice A } \\
\text { Week }\end{array}$ & $\begin{array}{l}\text { More Than Three } \\
\text { Times A Week. }\end{array}$ \\
\hline & & & & \multirow{2}{*}{$66 \%$} & \multirow{2}{*}{$34 \%$} \\
\hline & $61 \%$ & $35 \%$ & $4 \%$ & & \\
\hline
\end{tabular}

Table 4. Maximum daily dose taken by participants in comparison to daily recommended dose

\begin{tabular}{|l||l|l|}
\hline Analgesics & Maximum Daily Dose Taken By Participants & Daily Recommenced Dose \\
\hline Acetaminophen & $2000 \mathrm{mg} /$ day & $4000 \mathrm{mg} / \mathrm{day}$ \\
\hline Ibuprofen & $3000 \mathrm{mg} /$ day & $3200 \mathrm{mg} / \mathrm{day}$ \\
\hline Naproxen & $250-500 \mathrm{mg} /$ day & $1000 \mathrm{mg} / \mathrm{day}$ \\
\hline
\end{tabular}

${ }^{\star}$ Some participants were taking acetaminophen besides a prescription combination analgesic medication containing acetaminophen. We were unable to decide whether the consolidated absolute acetaminophen recommended dose of the nonprescription analgesic product surpassed the extreme suggested dose

the consolidated absolute acetaminophen recommended dose of the non-prescription analgesic product surpassed the extreme suggested dose.

\section{Discussion}

Pain treatments are safe and efficacious when used as directed. On the other hand, misuse of these medications can be harmful and even fatal. The majority of patients visit clinics to monitor painful conditions. Nevertheless, before taking treatment, a significant number of these patients will self-cure with NPA, and some will unexpectedly ingest too much of these substances. The goal of this study is to identify the utilize, of NPA amongst the population in Hail city. In this study, the majority of the participants were women, and this is because women are already using more NPA, a fact many studies have confirmed ${ }^{9,10}$. The largest percentage of the participants were young people, and this reflects the greater use of NPA in the youth group: another result observed across many studies ${ }^{11}$. Most study participants were from the educated, which indicates that analgesics use is widespread among all educational levels, which has been mentioned in many studies ${ }^{12}$. Because these medicines do not require a prescription, most participants used them without referring to a doctor, although very few return to taking the doctor's advice if the dose needed to be increased. Many studies reflect this same method, which is to take analgesics without identification and at any time when needed ${ }^{13}$. Often, chronic pain is associated with medical conditions, such as joint degeneration, autoimmune disorders, or diseases. The most common chronic pain conditions described in this study were headache and migraine, menstrual cycle pain, osteoarthritis, rheumatoid arthritis, myocardial infarction, neuropathy, and kidney disorders, respectively. These diseases have been mentioned in many studies and have been responsible for painful conditions in people who suffer from them ${ }^{14,15}$. The largest group of analgesics used by the participants in this study were acetaminophen as a non-prescription preparation, followed by NSAIDs and amphetamine-like products. These medications are also by far the most commonly used analgesics, as reported in many research studies ${ }^{16,17}$. Numerous reports from the Food and Drug Administration (FDA) outline the common health problems attributable to usage of amphetamine-like products. Using these substances as NPA was also found in this study, which adds support for more FDA involvement, as this is not the first report of misuse of amphetamine-like products. Medicinally, it won't upgrade the recommended doses, yet couple of individuals will take a portion a lot higher than the standard portion for these stimulants, and there lies the danger that should be highlighted in our upcoming research ${ }^{18}$. In addition, there is a need to foster rigid administrative systems to prevent abuse of NPA drugs. In this study that 
most participants were using a single non-prescription analgesic, while the combination analgesic products were used less often. Because we only collected dose data for NPA, we were unable to set whether the consolidated complete acetaminophen dose from the over-the-counter analgesic product was more noteworthy than the greatest suggested dose of acetaminophen in these patients. Most patients did not exceed the highest daily advised dose of acetaminophen, ibuprofen, naproxen, or combination products, and this differed from other reported studies in which patients exceeded the maximum manufacturer recommended daily dose ${ }^{19-21}$. The use of NPA is common among Hail residents, but most people use these products in moderation and do not exceed the recommended dose. Acetaminophen is one of the most commonly used products, but people also use NSAIDs to a limited extent, so exposing patients to an increased risk of adverse effects from these products is unlikely, and this demonstrates that individuals in this district have adequate consciousness of the dangers of extreme utilization of NPA.

\section{Conclusions}

NPA use is common among the population in Hail city. Acetaminophen is the most widely used product, but people also use NSAIDs and amphetamine-like products. Study participants are familiar with reading the patient information leaflet and knowing of the dosages used with these drugs, so their exposure to the side effects resulting from overuse considered unlikely. Patients should always remember to contact their physicians and let them know if they need to take analgesic medications for a long while so the appropriate management can be done, and the onset of medication overuse can be avoided. Further examination of such investigations could upgrade our consciousness of pain relieving abuse by the number of inhabitants in Hail city.

\section{Study Limitations}

One of the most important limitations of this study is the small sampling of participants. In addition, we failed to meet the targeted number of participants due to the coronavirus pandemic. Furthermore, reasons other than diseases for excessive use of NPA were not discussed in this study. Finally, this research did not develop solutions nor educate people about the potential risks of overuse of NPA, and this is something that we look forward to working on soon.

\section{Conflict of Interest}

The authors declare that there is no any conflict of interest.

\section{References}

1. OTC Analgesics Market Forecast, Trend Analysis \& Competition Tracking: Global Market insights 2017 to 2022 [online]. Available at: https://www.factmr.com/report/75/ otc-analgesics-market. Accessed: May 23, 2022.

2. Thomas SH, Shewakramani S. Prehospital trauma analgesia. The Journal of emergency medicine. 2008; 35(1): 47-57. https://doi.org/10.1016/j.jemermed.2007.05.041.

3. Moore RA, Wiffen PJ, Derry S, Maguire T, Roy YM, Tyrrell L. Non-prescription (OTC) oral analgesics for acute pain-an overview of Cochrane reviews. Cochrane Database of Systematic Reviews. 2015; (11). https://doi. org/10.1002/14651858.CD010794.pub2.

4. Heard KJ, Ries NL, Dart RC, Bogdan GM, Zallen RD, Daly F. Overuse of non-prescription analgesics by dental clinic patients. BMC Oral Health. 2008; 8(1): 1-5. https://doi. org/10.1186/1472-6831-8-33.

5. Hail, Saudi Arabia Metro Area Population 1950-2021 [online]. Available at: https://www.macrotrends.net/cities/22418/hail/population. Accessed: May 24, 2022.

6. Iwoi DMW, Nde PF, Yuh E, Kwenti ET, Tshimwanga EK, Achiri DT, et al. Assessment of the level of knowledge, attitude, and practice with regard to care of people living with HIV/AIDS among nursing and midwifery students in Fako, Cameroon. World Journal of AIDS. 2017; 7(1): 1-15. https://doi.org/10.4236/wja.2017.71001.

7. Acute vs. Chronic Pain [online]. Available at: https:// my.clevelandclinic.org/health/articles/12051-acute-vschronic-pain. Accessed: May, 24, 2022.

8. Pentel, P. Toxicity of over-the-counter stimulants. Jama. 1984; 252(14): 1898-1903. https://doi.org/10.1001/ jama.1984.03350140044023.

9. Hargreave M, Andersen TV, Nielsen A, Munk C, Liaw KL, \& Kjaer SK. Factors associated with a continuous regular analgesic use-a population-based study of more than 45000 Danish women and men 18-45 years of age. Pharmacoepidemiology and drug safety. 2010; 19(1): 65-74. https://doi.org/10.1002/pds.1864.

10. Felício AC, Bichuetti DB, Santos WACD, Godeiro Junior CDO, Marin LF, Carvalho DDS. Epidemiology of primary and secondary headaches in a Brazilian tertiary-care center. 
Arquivos de neuro-psiquiatria. 2006; 64(1): 41-44. https:// doi.org/10.1590/S0004-282X2006000100009.

11. Whiteside RM, Cunningham EE, Bonar F, Ehrlich P, Walton MA. Nonmedical prescription stimulant use among youth in the emergency department: prevalence, severity and correlates. J Subst Abuse Treat. 2015; 48: 21-7. https://doi. org/10.1016/j.jsat.2014.05.003.

12. Almalak H, Alkhelb DA, Alsaleh HM, Khan TM, Hassali MAA, Aljadhey H. Students' attitude toward use of over the counter medicines during exams in Saudi Arabia. Saudi Pharmaceutical Journal. 2014; 22(2): 107-112. https://doi. org/10.1016/j.jsps.2013.02.004.

13. Park HJ, Moon DE. Pharmacologic management of chronic pain. The Korean journal of pain. 2010; 23(2): 99. https:// dx.doi.org/10.3344\%2Fkjp.2010.23.2.99.

14. Kasasbeh MAM, McCabe C, Payne S. Cancer-related pain management: A review of knowledge and attitudes of healthcare professionals. European journal of cancer care. 2017; 26(6): e12625. https://doi.org/10.1111/ecc.12625.

15. What Causes Chronic Pain [online]. Available at: https:// www.webmd.com/pain-management/guide/cause-chronic-pain. Accessed: May 25, 2022.
16. Lake CR. Manic psychosis after coffee and phenylpropanolamine. Biological psychiatry. 15 Aug 1991; 30(4): 401-4. https://doi.org/10.1016/0006-3223(91)90296-X.

17. Golar SK. Use and understanding of analgesics (painkillers) by Aston university students. Bioscience Horizons. 2011; 4(1): 71-78. https://doi.org/10.1093/biohorizons/hzr009.

18. Gauvin DV, Moore KR, Youngblood BD, Holloway FA. The discriminative stimulus properties of legal, over-thecounter stimulants administered singly and in binary and ternary combinations. Psychopharmacology. 1993; 110(3): 309-319. https://doi.org/10.1007/BF02251286.

19. Preshaw PM, Meechan JG, Dodd MD. Self-medication for the control of dental pain: what are our patients taking? Dental update. 1994; 21(7): 299-301. PMID: 7875365.

20. Golar SK. Use and understanding of analgesics (painkillers) by Aston university students. Bioscience Horizons. 2011; 4(1): 71-78. https://doi.org/10.1093/biohorizons/hzr009.

21. Fernandes MTP, Hernandes FB, de Almeida TN, Sobottka VP, Poli-Frederico RC, Fernandes KBP In: Cecilia M, editor. Pain Relief: From Analgesics to Alternative Therapies. $1^{\text {st }}$ ed. Croatia: c2017. p. 47-62. https://doi.org/10.5772/67299. 